\title{
Characterisation of silver nanoparticles produced by three different methods based on Borohydride reducing agent
}

\author{
Roslinda Hani Ramli ${ }^{1,3}$, Chin Fhong Soon ${ }^{1,2,}$, Anika Zafiah Mohd Rus ${ }^{3}$ \\ ${ }^{1}$ Biosensor and Bioengineering Laboratory, MiNT-SRC, Universiti Tun Hussein Onn Malaysia, \\ 86400 Parit Raja, Johor, Malaysia \\ ${ }^{2}$ Faculty of Electric and Electronic Engineering, Universiti Tun Hussein Onn Malaysia, 86400 Parit \\ Raja, Johor, Malaysia \\ ${ }^{3}$ Faculty of Mechanical and Manufacturing Engineering, Universiti Tun Hussein Onn Malaysia, \\ 86400 Parit Raja, Johor, Malaysia
}

\begin{abstract}
This work reports the preparation and characterisation of silver nanoparticles (AgNPs) through chemical reduction method with three different procedures denote as modified Mulfinger's Method, Mulfinger's Method and Malina's Method. The yellow colloidal solution were characterised and analysed using Field Emission Scanning Electron Microscopy (FESEM), Energy Dispersive X-ray Spectroscopy (EDS), X-Ray Diffraction (XRD). FESEM and EDS analyses confirmed that the formation of AgNPs in Malina's Method with highest yield of silver (Ag), $67.39 \%$ weight as compared to Mulfinger's and modified Mulfinger's Method. The peaks in XRD pattern for Malina's Method are in good agreement with facecentered-cubic form of metallic silver while modified Mulfinger's Method and Mulfinger's Method XRD pattern suggest the halite/sodium chlorate and silver chlorate peaks respectively. Malina's Method is found to be a suitable method to study AgNPs.
\end{abstract}

\section{Introduction}

As of late, nanotechnology has gotten to be a standout amongst the most essential and energizing cutting edge fields in physics, material science, engineering, biology and also chemistry [1]. Nanotechnology is connected with the field of manufacture, characterisation, manipulative and utilisation of structures on a nano scale. Because of the nano-scaled size (1-100 $\mathrm{nm}$ ), nanoparticles have altogether enhanced biological, chemical, and physical properties [2]. Various changes in physical properties are because of the transformation from smaller scale particles (micro-sized) to the nanoparticles [1]. The expansion in the

${ }^{*}$ Corresponding author : soon@uthm.edu.my 
surface-to-volume proportion is a steady movement as the molecule gets smaller, induce the expanding strength and response of atoms on the surface of the molecule [1].

Wet chemical synthesis is normally used to incorporate metallic nanoparticles in which the chemicals utilized are regularly toxic and combustible. Moreover, biosynthesis could likewise be connected to integrate metallic particles yet the utilizing of this strategy still faces the challenge to isolate the nanoparticles, decreased purity and inconsistent response or behaviour of particles [3]. Noble metal nanoparticles has pulled in much consideration, because of their prevalent chemical and physical characteristic [4]. Silver nanoparticles (AgNPs) have occupied the consideration of the specialists because of its novel substance, physical, and natural properties, particularly their adequacy against microorganisms, used to reduce inflammation and wound curing ability [5].

There are various utilisations of nanoparticles, for example, for biological, physical and pharmaceutical applications [6]. The imperative properties of the silver-based composite are non-toxic, antibacterial and inorganic characteristic [7]. Public places, for example, railway stations and lifts in China, silver nanoparticles has been utilised widely as antimicrobial agents [6]. It was accounted in 1889, M. C. Lea firstly synthesised the silver colloid-stabilized by citrate with a normal breadth of 7-9 $\mathrm{nm}$ [8].

The most frequent and most applied method to prepare the silver nanoparticles with stable properties is by the chemical reduction method. Borohydride $\left(\mathrm{NaBH}_{4}\right)$ and citrate are reducing agents that frequently used to reduce silver-containing salt in the midst of production of nanosilver particles [6]. Polyvinylpyrrolidone (PVP) was utilised as a stabiliser in the synthesis of the silver nanoparticles [9]. Biocompatibility, universal soluble both in water and polar solvents and has fantastic wetting properties are the unique properties of Polyvinylpyrrolidone (PVP) [9].

Colloidal silver with molecule breadths of a few nanometers were yielded by the reduction of silver ions $\left(\mathrm{Ag}^{+}\right)$in aqueous solution [6]. The reduction of different edifices with $\mathrm{Ag}^{+}$particles leads to the formation of silver atoms and followed by agglomeration of silver nanoparticles into oligomeric bunches [6]. These bunches in the long run prompted the development of colloidal silver particles [6].

The objectives of this work were performed to study the properties and compare the yield of Silver (Ag) produced using different methods such as (a) modified Mulfinger's method, (b) Mulfinger's method and (c) Malina's method. The summary of the three methods is as listed in Table 1. Malina's method does not involve the usage of the ice bath during the experiment and polyvinyl pyrrolidone (PVP) was added as a stabiliser before the formation of yellow silver colloidal solution. While the difference between modified Mulfinger's method and Mulfinger's method is that Mulfinger's method originally does not involve the addition of sodium chloride $(\mathrm{NaCl})$ to check the stability of nanoparticles and difference of volume $\mathrm{AgNO}_{3}$ and PVP added. These differences may produce different yields and composition of silver. Thus, this research was conducted to investigate, compare the three methods and identifying which method produces the highest yield of Ag. 
Table 1. Comparison of methods for producing silver nanoparticles.

\begin{tabular}{|l|l|l|}
\hline $\begin{array}{l}\text { Modified Mulfinger's } \\
\text { method [10] }\end{array}$ & Mulfinger's method [11] & Malina's method [12] \\
\hline $\begin{array}{l}\text { Involve the usage of the } \\
\text { ice bath to reduce the } \\
\text { decomposition } \mathrm{NaBH}_{4}\end{array}$ & $\begin{array}{l}\text { Involve the usage of the ice } \\
\text { bath to reduce the } \\
\text { decomposition } \mathrm{NaBH}_{4}\end{array}$ & $\begin{array}{l}\text { Mixture prepared at room } \\
\text { temperature, 25 }{ }^{\circ} \mathrm{C} \text {. }\end{array}$ \\
\hline $\begin{array}{l}\text { PVP (stabiliser) was } \\
\text { added after the formation } \\
\text { of yellow silver colloidal } \\
\text { solution }\end{array}$ & $\begin{array}{l}\text { PVP (stabiliser) was added } \\
\text { after the formation of } \\
\text { yellow silver colloidal } \\
\text { solution }\end{array}$ & $\begin{array}{l}\text { PVP (stabiliser) was added } \\
\text { before the formation of } \\
\text { yellow silver colloidal } \\
\text { solution }\end{array}$ \\
\hline $\begin{array}{l}\text { Involves an addition of } \\
\text { sodium chloride (NaCl) to } \\
\text { check the stability of } \\
\text { AgNPs }\end{array}$ & $\begin{array}{l}\text { Not involve the addition of } \\
\text { sodium chloride (NaCl) }\end{array}$ & $\begin{array}{l}\text { Not involve the addition of } \\
\text { sodium chloride (NaCl) }\end{array}$ \\
\hline $\begin{array}{l}\text { Produced particles with } \\
\text { range 1-10 nm }\end{array}$ & $\begin{array}{l}\text { Produced particles with } \\
\text { range 10-14 nm }\end{array}$ & $\begin{array}{l}\text { Produced particles with non } \\
\text { uniform size distribution }\end{array}$ \\
\hline $\begin{array}{l}\text { Energy Dispersive Xray } \\
\text { Spectroscopy (EDS) } \\
\text { confirms the presence of } \\
\text { AgNPs }\end{array}$ & $\begin{array}{l}\text { No elemental analysis has } \\
\text { been conducted in paper }\end{array}$ & $\begin{array}{l}\text { Energy Dispersive Xray } \\
\text { Spectroscopy (EDS) confirms } \\
\text { the presence of AgNPs }\end{array}$ \\
\hline
\end{tabular}

\section{Materials and methods}

\subsection{Preparation of silver nanoparticles (modified Mulfinger's method)}

Firstly, $30 \mathrm{ml}$ of $0.002 \mathrm{M}$ of sodium borohydride $\left(\mathrm{NaBH}_{4}\right)(\mathrm{QRec}$, Asia) was added to a conical flask. The flask was placed in an ice bath and a solution was stirred with magnetic stirrer (Thermo Scientific, US) for 1 minute. To reduce the decomposition during the experiment, an ice bath was used in the experiment. Then, $2 \mathrm{ml}$ of $0.001 \mathrm{M}$ silver nitrate $\left(\mathrm{AgNO}_{3}\right)(\mathrm{QRec}, \mathrm{Asia})$ was added into the $\mathrm{NaBH}_{4}$ solution at approximately $10 \mu \mathrm{l}$ per second. The stirring was stopped as soon as all of $\mathrm{AgNO}_{3}$ was added into $\mathrm{NaBH}_{4}$ solution. Yellow colloidal suspension of silver nanoparticles should be formed at this stage. The reflection of a laser beam from the particles indicates the presence of a colloidal suspension. Next, $1 \mathrm{ml}$ of the yellow colloidal solution of silver was transferred into a glass test tube. Approximately $100 \mu 1$ of $1.5 \mathrm{M}$ sodium chloride $(\mathrm{NaCl})$ (Qrec, Asia) then was added to the test tube. $\mathrm{NaCl}$ solution was added to check the stability of silver nanoparticles formed. If the nanoparticles were unstable and has formed aggregates, further addition of $\mathrm{NaCl}$ will cause yellow colloidal solution to turn darker yellow, then gray. Subsequently, $200 \mu \mathrm{L}$ of PVP (QRec, Asia) at $0.3 \%(\mathrm{v} / \mathrm{v})$ was added into the test tube to prevent aggregation. Silver nanoparticles are ready to be used for the next experiment [10].

\subsection{Preparation of silver nanoparticles (Mulfinger's method)}

For preparation of silver nanoparticles, $30 \mathrm{ml}$ of $0.002 \mathrm{M}$ of $\mathrm{NaBH}_{4}$ was added to a conical flask. The solution was stirred with magnetic stirrer for 20 minutes flask and placed in an ice bath. $10 \mathrm{ml}$ of $0.001 \mathrm{M} \mathrm{AgNO}_{3}$ was added into stirring $\mathrm{NaBH}_{4}$ solution at 
approximately $10 \mu \mathrm{l}$ per second. The stirring was stopped as soon as all of $\mathrm{AgNO}_{3}$ was added into $\mathrm{NaBH}_{4}$ solution. At this stage, yellow colloidal suspension of silver nanoparticles should be formed. The reflection of a laser beam from the particles indicates the presence of a colloidal suspension. Next, $5 \mathrm{ml}$ yellow colloidal solution were transferred into a test tube. Then $20 \mu \mathrm{L}$ of PVP $0.3 \%$ solution was added into the test tube to prevent aggregation [11]. Silver nanoparticles are ready to be used for the next experiment. The difference between modified Mulfinger's method and Mulfinger's method is that Mulfinger's method originally does not involve $\mathrm{NaCl}$ to check the stability of nanoparticles and difference of volume $\mathrm{AgNO}_{3}$ and PVP added. However, the concentration of the borohydride and silver nitrate solutions are similar.

\subsection{Preparation of silver nanoparticles (Malina's method)}

Firstly, $100 \mathrm{ml}$ PVP $0.3 \%$ (v/v) solution was prepared by dissolving PVP in distilled water. This PVP solution was divided by two in separated polystyrene tubes, each with $95 \mathrm{ml}$ PVP $0.3 \%$ (solution A) and $5 \mathrm{ml}$ PVP $0.3 \%$ solution (solution B) respectively. Then, solution A was added to $0.039 \mathrm{~g}$ of $\mathrm{AgNO} 3$ and allowed to dissolve by stirring constantly on a magnetic stirrer plate for 10 minutes. While in another polystyrene tube, $0.17 \mathrm{mg} \mathrm{NaBH} 4$ was dissolved in solution B to produce borohydride solution. Solution B was added drop wise to solution $\mathrm{A}$ at a rate of $10 \mu \mathrm{l} / \mathrm{sec}$ after the complete dissolution of silver nitrate. The reaction mixture was mixed vigorously at room temperature for $15 \mathrm{~min}$ [12]. Then, silver nanoparticles were ready to be used for the subsequent experiment.

\subsection{Physical characterisation}

Characterisation of the yellow colloidal solution was performed by Field Emission Scanning Electron Microscopy (FESEM), Energy Dispersive X-ray Spectroscopy (EDS), and X-ray Diffraction (XRD). To examine the physical structrues of the silver nanoparticles produced, the samples were first prepared by dispersing the synthesised yellow silver colloidal solution on a glass substrate and left air dried at room temperature, $25{ }^{\circ} \mathrm{C}$. Images of the silver colloids were obtained using the Field Emission Scanning Electron Microscopy (FESEM, JEOL JSM-7600F) and elements of the silver colloids were investigated using EDS detector of the FE-SEM. The X-ray Diffraction (XRD) analysis of the silver colloids was studied using a X'pert PRO PANalytical diffractometer. The samples of silver colloids were investigated using $\mathrm{C}-\mathrm{K} \alpha$ X-rays at a wavelength $(\lambda)$ of $1.54060 \dot{\mathrm{A}}$ and the detected data was taken in a $2 \Theta$ range of $10^{\circ}$ to $120^{\circ}$ with a step size of $0.02^{\circ}$. All the characterisation experiments were repeated three times.

\section{Results and discussion}

\subsection{The physical structures and elements of the silver nanoparticles}

The specimens arranged by modified Mulfinger's, Mulfinger's and Malina's method created comparative yellow, clear and transparent aqueous solution in the vicinity of PVP, in which PVP functions as a stabilising agent in preventing aggregation [11]. In any case, this work recognized that the yield, creations and physical properties of the silver nanoparticles delivered utilizing the three techniques are for sure distinctive. The micrographs of FESEM 
depicted as in Figures 1 and 2. As shown in Figure 1 (a, b), observed that there are large crystals on $800 \times$ magnifications where the presence of the $\mathrm{NaCl}$ crystals is apparent and it is confirmed by EDS elemental analysis on modified Mulfinger's method. While as shown in Figures 1 (d) and $2(\mathrm{~b})$, silicon $(\mathrm{Si})$ and oxygen $(\mathrm{O})$ peaks are associated with the glass slide that was used as substrate to hold the sample during the microscopy. This also explains the presence of $\mathrm{O}$ in EDS result of modified Mulfinger's method. Besides, modified Mulfinger's method shows sodium $(\mathrm{Na})$ and chlorine $(\mathrm{Cl})$ peak is dominant due to the addition of $\mathrm{NaCl}$ in the system. In contrast, elements of $\mathrm{Na}$, magnesium $(\mathrm{Mg})$ and calcium $(\mathrm{Ca})$ were identified in EDS data by Mulfinger's method, whereas $\mathrm{Cl}$ was found in EDS data by Malina's method. However, for Malina's method, based on FESEM and EDS analysis of samples produced, Malina's method indicated highest level of silver element at a weight $67.39 \%$.

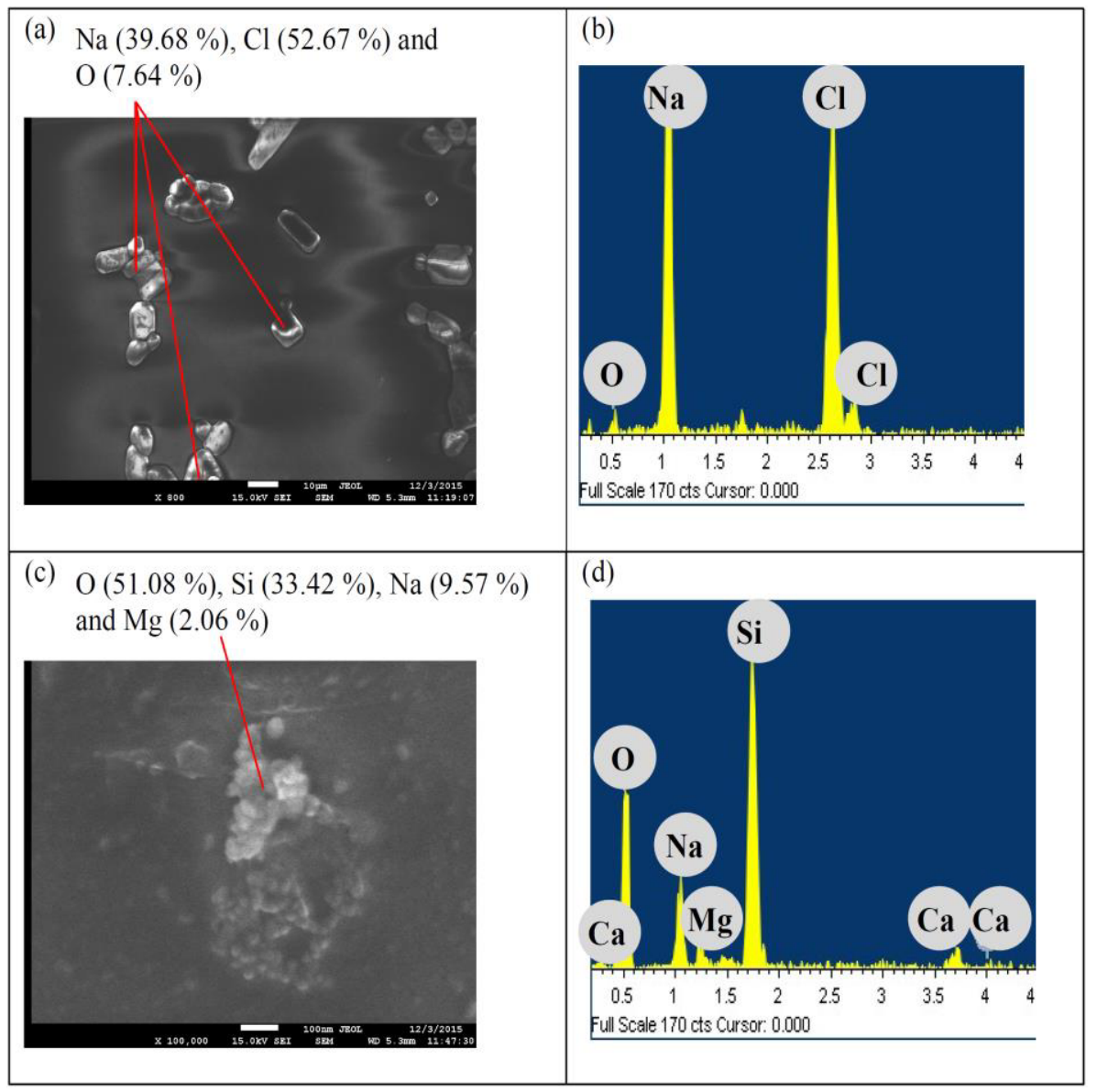

Fig. 1. FESEM image and EDS result of yellow colloidal solutions produced by modified Mulfinger's Method (a,b), Mulfinger's Method (c,d). 


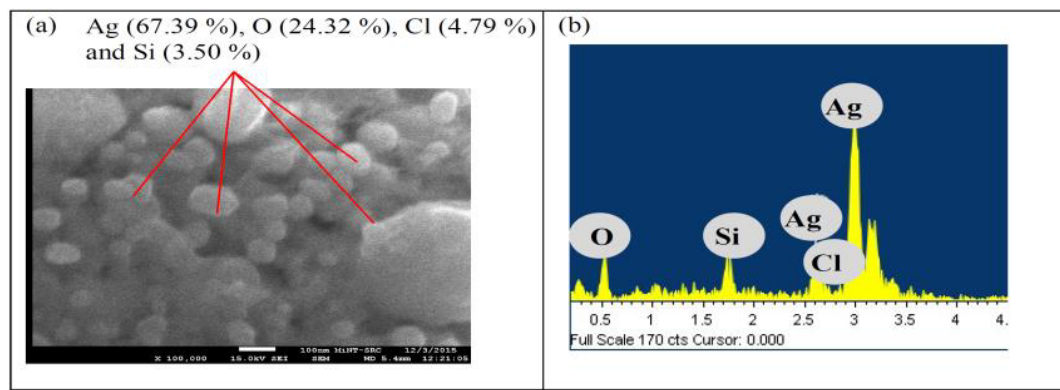

Fig. 2. FESEM image and EDS result of yellow colloidal solutions produced by Malina's Method $(\mathrm{a}, \mathrm{b})$.

FESEM images, elemental analysis with EDS confirmed the presence of silver nanoparticles in Malina's method. Modified Mulfinger's and Mulfinger's method indicated the absence of silver (Ag) peaks.

\subsection{X-ray diffraction analysis (XRD)}

According to Figure 3, the XRD result of modified Mulfinger's method, the peaks at $31.57^{\circ}$ (200) and $54.05^{\circ}(231)$ peaks are associated with sodium chlorate (ICSD no: 98-008-0341), while the peaks of $31.74^{\circ}(200), 53.88^{\circ}(311)$ and $75.34^{\circ}(420)$ are associated with halite (ICSD no: 98-005-2232) . There were no pure silver element found for the modified Mulfinger's method. However, peak $38.05^{\circ}$ (111) of silver chlorate and silver (ICSD no: 98-018-0878) were identified for Mulfinger's method. Nonetheless, more encouraging results were found for Malina's method in which all peaks at $38.1^{\circ}$ (111), $44.3^{\circ}$ (200), $64.55^{\circ}(220)$ and $77.56^{\circ}(311)$ are associated with the pure silver (ICSD no: 98-005-3761) [4]. Hence, the XRD peaks confirmed the presence of pure silver peaks in Malina's method as compared with modified Mulfinger's and Mulfinger's method.

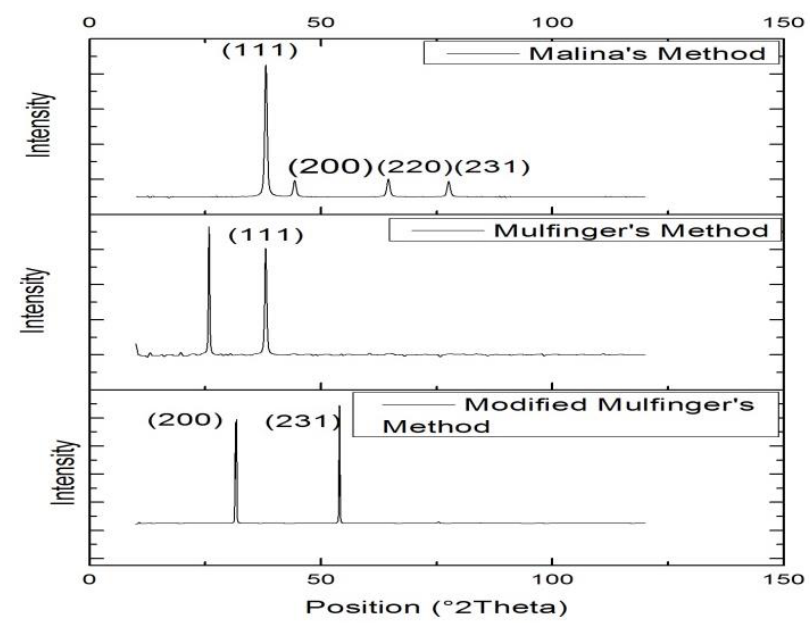

Fig. 3. XRD data of yellow colloidal solutions of modified Mulfinger's ,Mulfinger's and Malina's Methods. 


\section{Summary}

In the experiments connected with the present work, colloidal silver nanoparticles stabilised with PVP was successfully prepared by oxidation-reduction reaction in sodium borohydride and silver nitrate in aqueous solution. Based on FESEM and EDS result, modified Mulfinger's method show $\mathrm{Na}$ and $\mathrm{Cl}$ peak is dominant due to the addition of $\mathrm{NaCl}$ in the system. In contrast, elements of $\mathrm{Na}, \mathrm{Mg}$ and $\mathrm{Ca}$ were indentified in EDS data of Mulfinger's method. However, for Malina's method, EDS analysis of samples indicated highest level of silver element at a weight $67.39 \%$. In addition, the peaks in XRD pattern for Malina's method are in good agreement with face-centered-cubic form of metallic silver while modified Mulfinger's method and Mulfinger's method XRD pattern suggest the halite/sodium chlorate and silver chlorate peaks respectively. Malina's method is found to be a suitable method to study AgNPs. In conclusion, the properties and Ag yield of yellow colloidal solution of modified Mulfinger's method, Mulfinger's method and Malina's method were succesfully investigated in this research paper. Malina's method proved to produce high yield of Ag content and found to be a suitable method to study AgNPs.

We would like to thank Universiti Tun Hussein Onn Malaysia (UTHM) and the authors are grateful to the research financial support (ERGS E018) awarded by Universiti Tun Hussein Onn Malaysia. We also would like to thank Miss Isrehetty and Madam Faezahana for their technical supports.

\section{References}

1. S.M. Landage, A.I. Wasif, P. Dhuppe, International Journal of Advanced Research in Engineering and Applied Sciences, 3, 14(2014)

2. V. Sarsar, M.K. Selwal, K.K. Selwal, Journal of Saudi Chemical Society 19, 682 (2015)

3. T. Theivasanthi, M. Alagar, Nano Biomed. Eng., 4 (2011)

4. M.A.M. Khan, S. Kumar, M. Ahamed, S.A. Alrokayan, M.S. Alsalhi, Nanoscale Res. Lett., 6, 1 (2011)

5. A. Haider, I.K. Kang, Advances in Materials Science (2015)

6. S. Prabhu, E.K. Poulose, Int. Nano Lett., 2, 1 (2012)

7. P. Rauwel, E. Rauwel, S. Ferdov, M.P. Singh, Advances in Materials Science (2015)

8. B. Nowack, H.F. Krug, M. Height, Environ. Sci. Technol. Lett., 45, 1177 (2011)

9. N. Giri, R.K. Natarajan, S. Gunasekaran, S. Shreemathi, Arch. Appl. Sci. Res. 3, 624 (2011)

10. M.F. Alsayed, A.A. Shoeib, A.A. Hindi, M.A. Awad, K.M.O. Ortashi, Dig. J. Nanomater. Biostruct., 10 (2015)

11. L. Mulfinger, S.D. Solomon, M. Bahadory, A.V. Jeyarajasingam, S.A. Rutkowsky, C. Boritz, J. Chem. Educ., 84, 322 (2007)

12. D. Malina, A. Sobczak. Kupiec, Z. Wzorek, Z. Kowalski, Dig. J. Nanomater. Bios., 7, 1527(2012) 